\title{
When future teachers meet real learners through telecollaboration: an experiential approach to learn how to teach languages online
}

\author{
Marco Cappellini ${ }^{1}$ and Yu-Yin Hsu²
}

\section{Abstract}

The integration of technology in language teaching has been one important topic in language education and teacher training. Teacher education has been one of the

_ aims of telecollaboration since the beginning of the 2000's. While the first pioneers worked with small groups of students (Develotte, Mangenot, \& Zourou, 2005; MüllerHartmann, 2006), more recent projects are widening the application of telecollaboration for teacher education (Baroni et al., 2019). In the present article we present an adaptation of the model of Le Français en (Première) Ligne (hereafter F1L) proposed by Develotte et al. (2005) in two telecollaborative projects aiming at developing trainees' techno-semiopedagogical competences.

Keywords: teacher training; online language teaching; experiential learning; techno-semiopedagogical competence.

\section{Introduction}

Teacher education has been one of the aims of telecollaboration since the early 2000's, first with pioneers who worked with small groups of students (Develotte et al., 2005; Müller-Hartmann, 2006),

1. Aix Marseille Univ, CNRS, LPL, Aix-en-Provence, France; marco.cappellini@univ-amu.fr; https://orcid.org/0000-0002-2086-061X

2. The Hong Kong Polytechnic University, Department of Chinese and Bilingual Studies; yu-yin.hsu@polyu.edu.hk; https://orcid.org/0000-0003-4087-4995

How to cite this article: Cappellini, M., \& Hsu, Y.-Y. (2020). When future teachers meet real learners through telecollaboration: an experiential approach to learn how to teach languages online. Journal of Virtual Exchange, 3, 1-11. https://doi.org/10.21827/jve.3.35751 
and more recently with large projects scaling up the extent and application of virtual exchange in (mostly pre-service) teacher training (Baroni et al., 2019).

One of the models of telecollaboration that contributed advance knowledge and practice to prepare foreign language teachers to online teaching and tutoring is F1L proposed by Develotte et al. (2005). In this model, pre-service teachers elaborate online tasks and administer them online to actual learners. This article presents how this model was extended in two directions. On the one hand, we adapted the model to the teaching of another foreign language: Mandarin Chinese. On the other hand, we developed this model for the trainee teachers to experience online language teaching through different platforms. The aim of this paper is to present how this adaptation was carried out and our observations about teacher training for the development of different types of techno-semiopedagogical competences.

In the Contexts section, we present how the two telecollaborative projects were implemented in the institutions and which were the cohorts of the 2019 iterations. In the following section, we will state the objectives of the two projects and their theoretical rationale. The Project design section presents the different stages of the two telecollaborative projects. Finally, in the Evaluation section, we draw on trainee teachers' questionnaires and reflective writings to understand their perception of the telecollaborative projects and to suggest further developments.

\section{Contexts}

The first telecollaborative project we examined was implemented between trainee teachers at the Hong Kong Polytechnic University (henceforth PolyU) and learners of Mandarin Chinese at AixMarseille University (henceforth AMU).

More precisely, the PolyU-AMU project was implemented among students in their first year of a Master's degree in teaching Chinese as a foreign language at the PolyU and second-year students in their Bachelor's degree in Chinese language, literature, and civilisation at AMU. The teacher trainees were native speakers of Mandarin from China, who had no previous in-class teaching experience, but had completed the basic teacher training courses (educational linguistics, and teaching methods) before participating in this project. Students of Chinese in Aix-en-Provence were at a B1 level of Chinese proficiency as is defined by the Common European Framework of Reference for languages (Council of Europe, 2001, hereafter CEFR). They were mainly French students, except for one Mexican student. This project involved ten students in total in 2019. The PolyU-AMU telecollaboration was at its third iteration in the spring of 2019. 
The second telecollaborative project was implemented between trainee teachers in AMU and learners of French in University of California Berkeley (henceforth UCB). Trainee teachers were in their first year of a Master's degree in didactique du français langue etrangère (didactics of French as a foreign language). Learners of French were second-year students enrolled in a course counting towards a minor in French in their Bachelor's degree. Students in Berkeley had proficiency in French at the B1 or B2 level. Future teachers of French were mainly French and for one third coming from different countries, including Algeria, Brazil, Colombia, and Russia. The majority of trainee teachers had no previous experience in teaching. This project involved about 50 students in total.

The two telecollaborations were integrated differently in the three institutions. In the PolyU-AMU project, the future teachers of Chinese participated voluntarily aiming to gain a more authentic teaching experience. As for the learners of Chinese, the telecollaborative project was integrated as part of ten hours of autonomous language learning required in their semester curriculum. The implementation at AMU was conducted by one of the authors at the local language centre. The language learning activities were developed according to the pedagogical materials and the course of learners of Chinese.

In the AMU-UCB project, the trainee teachers of French were enrolled in a course about online tutoring, in which the telecollaboration was the main part. The course was taught by two teachers, including one of the authors. As for the learners of French, the telecollaboration was part of a course exploring sustainable development issues in French society at UCB, taught by two teachers.

\section{The objectives}

The two main objectives of the telecollaboration projects were the development of communicative competence for language learners, and of pedagogical and digital competences for future teachers.

The two projects adopted the action-based perspective of the CEFR (Council of Europe, 2001) and were based on task-based language teaching (Ellis, 2003). Very briefly, learning tasks are defined as socially relevant actions that are carried out by the learners using their communicative competence, including using a foreign language. Following Dooly (2010), we shift the focus from single tasks to task sequences, where learners are guided through a series of tasks that form a coherent whole (see below). 
In the two telecollaborations, we aimed to develop the techno-semio-pedagogical competence (Guichon, 2012) of future language teachers. Since the early 2000's, research has shown that online teaching is not just the transposition of in-class teaching strategies into an online environment (Hampel \& Stickler, 2005), but that it has particular features that make it unique, be it for task design (Hampel, 2006) or online tutoring (Hampel \& Stickler, 2012). Guichon (2012) defines the technosemio-pedagogical competence as knowledge and skills about applying communication tools to the pedagogical objectives, relevant modalities for pedagogical activity and the development of language skills, and pedagogical management of activities with computer-mediated communication (p. 187).

To develop such a competence, the first step is to raise teachers' awareness of the characteristics of the online environment(s) in terms of the potentials and constraints for actions, that is affordances (Blin, 2016). However, studies such as Chao's (2015) have highlighted that there may be a 'transfer problem' to actual practice. In our case, this means that learning to analyse the affordances within an environment does not necessarily result in the ability to strategically elaborate those affordances during actual online teaching. To overcome this issue, we followed the recommendations of Müller-Hartmann (2006) to implement experiential learning for future teachers through telecollaboration, which Vinagre (2017) demonstrated to result in the development of procedural knowledge.

Experiential learning is nowadays fairly common in teacher training curricula for the development of online skills, and was modelled for instance in the recent report of the EVALUATE project (Baroni et al., 2019, p. 13) under the name of the Progressive Exchange Telecollaborative (PET) model. In this telecollaborative model, groups of future teachers go through a three-step process including three different online collaborative tasks. This allows them to develop, among others, their pedagogicaldigital competence through direct experience of online collaboration.

The model we choose, F1L, is similar to the PET model; while both models are based on experiential learning for teacher training, the F1L model differs significantly from PET in that the former requires the future teachers to administer online language learning tasks to real learners, while the latter focuses more on elaboration of tasks within telecollaboration. Therefore, F1L allows future teachers not only to have a direct experience of telecollaboration, but also to be exposed to the realtime and possibly unpredicted reactions and/or questions raised by the learners. Finally, within the F1L, the online interactions are subsequently analysed by trainee teachers through written reports (Cappellini \& Combe, 2017) or stimulated recalls under the teacher's supervision (Rivière \& Guichon, 2014), which leads, in the best cases, to the development of teaching strategies and techno-semiopedagogical competences. 


\section{Project design}

\subsection{Innovative aspects}

The two telecollaborations we describe extended the model of F1L (Develotte et al., 2005) in two new directions. The first innovation we present was implemented in the PolyU-AMU project, with the application of the F1L model to another language: Mandarin Chinese. This raised questions about the relationship between spoken and written language, manifested by choices such as the use or avoidance of pinyin (the romanisation system of Chinese words). The second innovation was implemented in the AMU-UCB project and it regards the environments that were used and the subsequent conceptualisation of techno-semio-pedagogical competences. The F1L model started in 2002 as an asynchronous exchange exploiting online forums.

When one of the initiators moved to Lyon, she started in 2006 to apply the model in desktop videoconference environments. In this way, within implementations of the F1L model, the future teachers developed competences that were different (Develotte \& Mangenot, 2010), for asynchronous environments in one case, and for audiovisual synchronous environments in the other. For the AMU-UCB telecollaboration we describe, our starting point was Hampel and Stickler's (2015) observation that "today a multitude of online spaces are available that have a potential for learning” (p. 63). Considering this, we decided to make the model evolve in order for future teachers to be able to deal with more than one type of environment rather than to become specialised in one (Cappellini \& Combe, 2017). Concretely, in the AMU-UCB project, the trainee teachers had to use both an asynchronous and a synchronous online environment: a Learning Management System (LMS) composed mainly of online forums (bCourses) and an audiovisual teaching platform (Adobe Connect); and had to learn to adapt their pedagogical actions to the online environments' differences.

\subsection{The PolyU-AMU project}

For the PolyU-AMU project, the exchanges included five weekly, 30 to 50 minute videoconferences through Skype between one trainee teacher and one learner. The role of the trainee teachers during each session was to introduce the activity, to scaffold learners' oral expression, and to provide feedback. Before the sessions, future teachers were instructed to establish a casual, conversational atmosphere during each exchange, to use only the target language, and to facilitate discussions based on the pre-assigned topic/tasks in each exchange. The videoconferences were arranged outside class hours by the students and their teachers, supervised by the two authors. The exchanges took place in the language centre and the speech lab at both universities. 
The topics of the weekly tasks were produced in order to follow the progression of the learners of Chinese in Aix-en-Provence. These tasks were not all linked to a single scenario, but were involved with multiple social and cultural topics. After the first ice-breaking activity, students discussed issues related to international mobility in higher education to propose ways to integrate international students in the two universities (Task 2), and to organise a weekend tour for international students (Task 3). Task 4 reproduced the same activity as the first task of the AMU-UCB telecollaboration (below), dealing with an analysis and discussion of documents regarding environmental issues. Finally, Task 5 was related to food preferences and cooking (see appendix for details). During all the exchanges, the trainee teachers served to facilitate discussions, to correct learners' speech errors, or to provide better phrasing, and they also provided feedback during discussion and reviews at the end of the exchange or at the beginning of the next exchange.

\subsection{The AMU-UCB project}

In the AMU-UCB project, first the future teachers developed three online tasks within a given scenario before the online exchange. The design of the tasks was supervised by the teacher trainers at AMU during their course hours. Second, during the asynchronous and synchronous online exchange, the future teachers administered the tasks to the UCB students.

In the task design stage, the future teachers were presented with current theories on online teaching/ tutoring, and were accompanied to design the three tasks of the scenario. The scenario aimed at letting the UCB students elaborate a chart for the organisation of a sustainable scientific event, this topic being chosen because it fitted with the UCB students' course of French. The first task was produced collectively by future teachers and consisted in a multimodal analysis (Bezemer \& Kress, 2016) and discussion of authentic documents about environmental issues, such as the UNESCO grid of sustainable development goals (see appendix). The second task was produced in pairs of future teachers and included an analysis of a chart for environmental issues. Each dyad of future teachers presented their task to the whole group to obtain feedback. The third task was also produced in pairs of future teachers and aimed at making the UCB students produce the aforesaid chart.

During the online exchanges, each AMU student tutored one or two UCB students, guiding them from an analysis of authentic documents to the production of the aforementioned chart. As mentioned above, the exchanges used an LMS platform and took place on a videoconferencing platform. First, the future teachers produced videos where they introduced themselves to their students before the exchanges and posted them on the LMS platform. The LMS platform was used mainly for communication and organising pedagogical materials and for dealing with the assignments in between the three 30 to 45 minute videoconferences. For the videoconferences, future teachers used 
the Adobe Connect platform (introduced during their course), which allows different configurations and adaptations to different pedagogical activities. The first two videoconferences took place during class hours, since it was possible to manage the schedules of the two courses accordingly. Due to an increased time gap, the third videoconference took place outside of class hours. For the future teachers, the assessment was conducted based on reflexive writing on their whole online teaching experience. For the learners, there was no particular assessment for their participation, but their exam was based partly on similar activities as the one carried out during the telecollaboration. Table 1 summarises the design of the two projects.

\section{Table 1. Overview of the telecollaboration projects}

\begin{tabular}{|c|c|c|}
\hline & PolyU-AMU & AMU-UCB \\
\hline Platforms & Skype & bCourses + Adobe Connect \\
\hline Group composition & Dyads & Dyads or triads \\
\hline Tasks & $\begin{array}{l}\text { 1. Ice-breaker } \\
\text { 2. Welcome international students } \\
\text { 3. Organise a weekend for international students } \\
\text { 4. Analysis of online documents on } \\
\text { sustainable development } \\
\text { 5. Food and cooking }\end{array}$ & $\begin{array}{l}\text { 1. Analysis of online documents on } \\
\text { sustainable development } \\
\text { 2. Analysis of a chart related to } \\
\text { environmental issues } \\
\text { 3. Production of a chart for the organisation } \\
\text { of a sustainable scientific event }\end{array}$ \\
\hline
\end{tabular}

\section{Evaluation/discussion of outcomes}

In this section, we ground our considerations on the trainee teachers' feedback received during the 2019 iterations of the two telecollaborations.

For the PolyU-AMU telecollaboration, we retrieved four questionnaires from the trainee teachers. In the questionnaire, students were asked what their impressions of the telecollaboration were, which links they saw with other courses of their curriculum of teacher training, what the strengths and weaknesses of the project were, and how the project could be improved.

The main links to theory from the courses of their curriculum involved the tenets of various methodologies for language teaching. Trainees developed an eclectic approach to their online teaching (Puren, 1994), drawing on different elements from various approaches, including the communicative approach, the direct method, and task-based language teaching. In particular, trainees reported their interest in centering the online sessions on the learner, leading to an active pedagogy where they (the trainee teachers) had to adjust to the situation (such as the flow of 
discussion, and the alternation of multimodal communication aids) and to the learners (such as spotting students' misunderstandings/difficulties, or giving feedback promptly).

The main strength perceived was the flexibility of distance learning, coupled with the nature of the interactions. Trainees reported a feeling of a "casual" conversation ${ }^{3}$, resulting in less pressure for the learners to express themselves only/mostly in the target language, which is a learning environment good for using the direct method. Trainees also found that the learners were more engaged in the conversation since the interaction was "more direct" 4 and since the students could relate to the conversation topics, given the pre-assigned tasks were mostly about student life. However, despite the 'casual' nature of the conversation for learners, the trainee teachers noted a need for the teacher to more carefully guide the conversation and adjust to their interlocutors. This point was perceived as a strength, but also as a weakness in one case. Finally, some students reported easier access to online resources during the interactions, such as pictures and dictionaries, as a strength of the telecollaborative, hence online, setting.

As for the weaknesses, they included the time gap between Hong Kong and France, and the focus exclusively on the practice of oral interaction. Some students reported on the limits linked to the technological environment, allowing limited use of body-language and sometimes generating technical problems needing technological competence. Among the suggestions, students included a need for more technical training in order to better use the online environment. The other suggestions were related to the integration of other forms of communication besides the videoconferencing sessions, in order to gain familiarity with the learners and their initial level of proficiency, and to accompany them with language content to be used before the session and with summaries sent by email after the sessions.

For the AMU-UCB project, the evaluation of the project was carried out using the reflective writings and online anonymous questionnaires of the trainee teachers. In the reflective writings, following a well-established tradition in computer assisted language learning teacher education (Son \& Windeatt, 2017), the students were asked to reflect, using the theoretical references presented during the course, about the pedagogical actions carried out during the project, including task design, instruction-giving, providing positive and negative feedback, and how this related to the environment they used and their affordances. Their reflection was to be linked to traces of their interactions, such as screen captures or recordings. In the anonymous online questionnaire, the students were asked if the telecollaboration interested them, if they found it difficult to use the

3. The original quotes were “随意”, “轻松愉快的交流”.

4. The original quote was “(简单)直接”. 
online platforms, which were the strengths and weaknesses of the project in their opinion, and how the telecollaboration could be improved.

We collected all the 24 reflective writings and 13 questionnaires. These show an awareness of the complexity of online language teaching informed by theoretical concepts to drive pedagogical practice, such as the zone of proximal development (Vygotsky, 1978), multimodality (Bezemer \& Kress, 2016), and affordances (Blin, 2016), among others. Some students also highlighted how this telecollaboration allowed them to build links with other courses of the curriculum, providing a concrete experience of concepts such as the focus on form in grammar teaching or the use of authentic documents. The most appreciated feature was the fact that they taught French to real learners, especially through the videoconference sessions. In the questionnaires, only $15 \%$ of the respondents showed interest in the asynchronous teaching, which leads us to think that the students were not sufficiently accompanied to understand how different types of online platforms can be used together. The most challenging aspect reported by trainee teachers was to be forced to watch themselves in the recordings of their videoconferencing sessions. Students also reported that they found the time-span of three videoconferences to be too short. Another aspect that needs to be improved is the motivation of their learners, which varied greatly among UCB students.

\section{Conclusions and implication}

The main objective of the two telecollaborative projects we presented is the development of techno-semio-pedagogical competences for language teachers teaching online through experiential learning. We defined these competences as awareness and ability to use the affordances of the online environments. Based on the reflective writings and online questionnaires collected, we showed that experiential learning is not only useful to raise trainee's awareness of some affordances, but it is also widely appreciated because future teachers and learners can engage in what they perceive as a more authentic communication. Experiencing telecollaboration also proved to provide an opportunity for trainee teachers to build links between the theoretical concepts presented in their curriculum and their practice of online teaching.

Some limits in terms of awareness were also visible from the data collected. For instance, trainee teachers in Hong Kong seemed to be still attached to the in-class context as their main framework of reference, to which they always compared their online experience. Another limit was, for the trainee teachers in Aix-en-Provence, the underuse of the asynchronous environment, which showed the lack of awareness of how the asynchronous environment was part of the ecology of the telecollaboration. To our surprise, a related aspect was made explicit by Hong Kong trainee 
teachers, who regretted the sole use of videoconference without an asynchronous platform. We therefore think that a particular orchestration about online teaching should be provided to trainee teachers in their future practice.

Finally, this report will need to be completed by sound research focusing not only on the reported perceptions of trainee teachers, but also on the data of the actual online interactions we collected (Cappellini \& Hsu, 2018). This will inform us on the possible gaps between perception and interaction, and therefore it will provide a window on the other side of techno-semio-pedagogical competence: the actual capacity to use affordances in online environments.

\section{Acknowledgements}

We would like to thank our colleagues Christelle Combe, Christine Graziani, Rick Kern and Vesna Rodic for their collaboration. This paper is part of a research project funded by the French ANR (https://anr.fr/Projet-ANR-18-CE28-0011).

\section{References}

Baroni, A., Dooly, M., Garcés García, P., Guth, S., Hauck, M., Helm, F., Lewis, T., Mueller-Hartmann, A., O’Dowd, R., Rienties, B., \& Rogaten, J. (2019). Evaluating the impact of virtual exchange on initial teacher education: a European policy experiment. Research-publishing.net. https://doi.org/10.14705/rpnet.2019.29.9782490057337

Bezemer, J., \& Kress, G. (2016). Multimodality, learning and communication. A social semiotic perspective. Routledge.

Blin, F. (2016). The theory of affordances. In C. Caws \& M.-J. Hamel (Eds), Language-learner computer interactions (pp. 41-64). John Benjamins. https://doi.org/10.1075/lsse.2.03bli

Cappellini, M., \& Combe, C. (2017). Compétences techno-sémio-pédagogiques d'apprentis tuteurs dans des environnements numériques. ALSIC, 20(3). https://doi.org/10.4000/alsic.3186

Cappellini, M., \& Hsu, Y.-Y. (2018). Ce que l'oculométrie peut apporter à une approche écologique aux échanges en ligne.

In C. Dejean-Thircuir, F. Mangenot, E. Nissen \& T. Soubrié (Eds), Actes du colloque Echanger Pour Apprendre en Ligne 2018. http://hal.univ-grenoble-alpes.fr/EPAL/hal-02023002

Chao, C.-C. (2015). Rethinking transfer: learning from Call teacher education as consequential transition. Language Learning \& Technology, 19(1), 102-118.

Council of Europe. (2001). Common European framework of reference for languages: learning, teaching, assessment. Cambridge University Press.

Develotte, C., \& Mangenot, F. (2010). Former aux tutorats synchrone et asynchrone en langues. Distances et savoirs, 8(3), 345-359. 
Develotte, C., Mangenot, F., \& Zourou, K. (2005). Situated creation of multimedia activities for distance learners: motivational and cultural issues. ReCALL, 17(2), 229-244.

Dooly, M. (2010). Teacher 2.0. In S. Guth \& F. Helm (Eds), Telecollaboration 2.0. Language, literacy and intercultural learning in the 21st Century (pp. 277-303). Peter Lang.

Ellis, R. (2003). Task-based language learning and teaching. Oxford University Press.

Guichon, N. (2012). Vers l'intégration des TIC dans l'enseignement des langues. Didier.

Hampel, R. (2006). Rethinking task design for the digital age. ReCALL, 18(1), 105-121.

Hampel, R., \& Stickler, U. (2005). New skills for new classrooms: training tutors to teach languages online. Computer Assisted Language Learning, 18(4), 311-26.

Hampel, R., \& Stickler, U. (2012). The use of videoconferencing to support multimodal interaction in an online language classroom. ReCALL, 24(2), 116-137.

Hampel, R., \& Stickler, U. (2015). Introduction. In R. Hampel \& U. Stickler (Eds.), Developing Online Language Teaching (pp. 1-11). Palgrave Macmillan.

Müller-Hartmann, A. (2006). Learning how to teach intercultural communicative competence via telecollaboration. In J. Belz \& S. L. Thorne (Eds), Internet-mediated intercultural foreign language education (pp. 63-84). Thomson and Heinle.

Puren, C. (1994). La didactique des langues étrangères à la croisée des méthodes. Essai sur l'éclectisme. Didier/Hatier.

Rivière, V., \& Guichon, N. (2014). Construction de bilans rétroactifs par des apprentis tuteurs de langue en ligne. Le Français dans le monde - Recherches et applications, 56, 118-135.

Son, J.-B., \& Windeatt, S. (2017). (Eds). Language teacher education and technology. Approaches and practices. Bloomsbory. Vinagre, M. (2017). Developing teachers' telecollaborative competences in online experiential learning. System, 64, 34-45.

Vygotsky, L. S. (1978). Mind in society. Harvard University Press.

\section{Appendices: pedagogic materials}

Appendix 1: https://journal.unicollaboration.org/article/view/35751/33641

Appendix 2: https://journal.unicollaboration.org/article/view/35751/33642 


\section{Virtual Exchange?}

Published by University of Groningen Press | UGP, a not-for-profit press

Groningen, The Netherlands | UGP@rug.nl

(C) 2020 UNICollaboration (collective work)

(C) 2020 by Authors (individual work)

Journal of Virtual Exchange 2020

Edited by Carolin Fuchs, Cecilia Kennedy, and Müge Satar

Publication date: 2020/05/18

Journal of Virtual Exchange (JVE) is an online, open-access, peer-reviewed journal aimed at practitioners and researchers in the field known variously as virtual exchange, telecollaboration, or online intercultural exchange. It is the official journal of UNICollaboration (https://www.UNICollaboration.org/), the international academic organisation dedicated to supporting and promoting telecollaboration and virtual exchange in higher-level education.

Rights. The whole volume is published under the Attribution-NonCommercial-NoDerivatives 4.0 International licence (CC BY-NCND 4.0); individual articles may have a different licence. Under the CC BY-NC-ND licence, the volume is freely available online for anybody to read, download, copy, and redistribute provided that the author(s), editorial team, and publisher are properly cited. Commercial use and derivative works are, however, not permitted.

Disclaimer. University of Groningen Press does not take any responsibility for the content of the pages written by the authors of this article. The authors have recognised that the work described was not published before, or that it was not under consideration for publication elsewhere. While the information in this article is believed to be true and accurate on the date of its going to press, neither UniCollaboration nor University of Groningen Press can accept any legal responsibility for any errors or omissions. Additionally, the publisher makes no warranty, expressed or implied, with respect to the material contained herein. While University of Groningen Press is committed to publishing works of integrity, the words are the authors' alone.

Trademark notice. Product or corporate names may be trademarks or registered trademarks, and are used only for identification and explanation without intent to infringe.

Copyrighted material. Every effort has been made by the editorial team to trace copyright holders and to obtain their permission for the use of copyrighted material in this article. In the event of errors or omissions, please notify the publisher of any corrections that will need to by incorporated in future editions of this article.

Typeset by Research-publishing.net (https://research-publishing.net)

Noto fonts are open source. All Noto fonts are published under the SIL Open Font License, Version 1.1. Noto is a trademark of Google Inc. (https://www.google.com/get/noto/).

ISSN: 2647-4832 (online only)

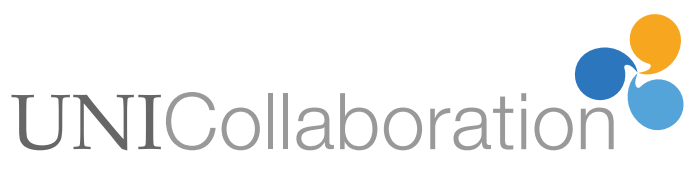

